\title{
Obesity-associated systemic interleukin-6 promotes pre- adipocyte aromatase expression via increased breast cancer cell prostaglandin E2 production
}

Laura W. Bowers,

Department of Nutrition, University of North Carolina at Chapel Hill, 135 Dauer Drive, McGavranGreenberg Hall, Chapel Hill, NC 27599, USA

\section{Andrew J. Brenner,}

Division of Hematology and Medical Oncology, University of Texas Health Science Center, 7703

Floyd Curl Drive, San Antonio, TX 78229, USA brennera@uthscsa.edu

\section{Stephen D. Hursting,}

Department of Nutrition, University of North Carolina at Chapel Hill, 135 Dauer Drive, McGavranGreenberg Hall, Chapel Hill, NC 27599, USA hursting@email.unc.edu

Rajeshwar R. Tekmal, and

Department of Obstetrics and Gynecology, University of Texas Health Science Center, 7703

Floyd Curl Drive, San Antonio, TX 78229, USA tekmal@uthscsa.edu

\section{Linda A. deGraffenried}

Department of Nutritional Sciences, University of Texas at Austin, 1400 Barbara Jordan Blvd, R1800, Austin, TX 78723-3092, USA degraffenried@austin.utexas.edu

\section{Abstract}

Obesity is associated with a worse breast cancer prognosis, particularly in estrogen receptor alpha (ERa) positive, postmenopausal patients. We hypothesized that this is mediated in part by an elevation in breast cancer cell cyclooxygenase-2 (COX-2) expression and prostaglandin E2 (PGE2) production that results in greater local pre-adipocyte aromatase expression. We utilized an in vitro model of the obese patient's tumor microenvironment in which cultured MCF-7 breast cancer cells and pre-adipocytes were exposed to pooled serum from obese (OB; BMI $\geq 30.0$ $\mathrm{kg} / \mathrm{m}^{2}$ ) or normal weight (N; BMI $18.5-24.9 \mathrm{~kg} / \mathrm{m}^{2}$ ) postmenopausal women. Exposure to OB versus N sera significantly increased MCF-7 cell COX-2 expression and PGE2 production. Preadipocyte aromatase expression was $89 \%$ greater following culture in conditioned media (CM) from MCF-7 cells exposed to OB versus N sera (OB-CM and N-CM, respectively), a difference nullified by MCF-7 cell treatment with the COX-2 inhibitor celecoxib. Previous analysis of the sera revealed significantly higher interleukin-6 (IL-6) concentrations in the OB versus N samples.

(C) Springer Science+Business Media New York 2014

laurawbowers@gmail.com.

Conflict of interest

The authors declare that they have no conflict of interest.

Ethical Standards

The experiments described here comply with the current laws of the country in which they were performed. 
Depletion of IL-6 from the sera neutralized the difference in pre-adipocyte aromatase expression stimulated by OB-CM versus N-CM. Finally, CM from pre-adipocyte/MCF-7 cell co-cultures exposed to OB sera stimulated greater MCF-7 and T47D breast cancer cell ERa activity and proliferation in comparison to $\mathrm{N}$ sera. This study indicates that obesity-associated systemic IL-6 indirectly enhances pre-adipocyte aromatase expression via increased breast cancer cell PGE2 production. Investigation regarding the efficacy of a COX-2 inhibitor/aromatase inhibitor combination therapy in the obese postmenopausal patient population is warranted.

\section{Keywords}

Obesity; Aromatase; Interleukin-6; Prostaglandin E2; Cyclooxygenase-2

\section{Introduction}

The majority of breast cancer cases occur in postmenopausal women [1], though tumors in this population are typically less aggressive than those occurring in younger women [2]. However, the obesity rate in women $\searrow 60$ years of age in the United States is currently 42.3 $\%$, the highest of any gender/age category [3], and this condition has been associated with a worse breast cancer prognosis. A 2010 meta-analysis of 43 studies found that obesity at diagnosis is associated with poorer breast cancer specific and overall survival [4], and others have shown that the strength of the latter association increases with each successive increase in body mass index (BMI) category [5]. Links between obesity and an increased risk of breast cancer recurrence and shorter disease-free survival [6,7], independent of tumor stage at diagnosis [8], have also been established.

Postmenopausal obesity is generally accompanied by an elevation in circulating estrogen levels because adipose tissue is the primary site of aromatase expression following menopause [9-11]. Consequently, some researchers have hypothesized that this excess estrogen may link obesity with more aggressive estrogen receptor alpha (ERa)-positive breast tumors in postmenopausal women, a theory supported by studies demonstrating a reduced response to aromatase inhibitor treatment in obese patients [12-14]. However, this explanation has been confounded by studies demonstrating that estrogen levels in breast tumor tissue can be up to tenfold higher than serum concentrations [15]. A corresponding fivefold elevation in aromatase expression in the tumor and associated adipose tissue in comparison to diseasefree tissue [15] suggests that this estrogen is being produced locally, likely via a paracrine interaction between the adipose and tumor tissues. In support of this possibility, O'Neill et al. [16] demonstrated in their analysis of 12 breast samples that the highest aromatase activity is consistently found in the tumor-containing breast quadrant. Zhou et al. [17] later established that breast cancer cell-secreted prostaglandin E2 (PGE2), as well as other factors, stimulates aromatase expression in preadipocytes, the primary aromatase-expressing fraction of the adipose tissue. These findings indicate that an elevation in systemic estrogen levels will probably not have a significant impact on breast tumor ERa activity, given that a much larger local source of estrogen is available in the tumor microenvironment and adjacent adipose tissue. 
However, aromatase and estrogen may still be key factors in the link between obesity and poor prognosis in ERa positive, postmenopausal breast cancer patients. Obesity is associated with increased circulating levels of several growth factors, cytokines, and adipokines that may enhance the paracrine interaction described above, resulting in a further elevation in local aromatase levels and estrogen production. For example, serum concentrations of interleukin-6 (IL-6), an inflammatory cytokine secreted by both immune cells and adipocytes, are generally increased with obesity [18], and this cytokine has been shown to promote PGE2 production in multiple cell types via its effects on cyclooxygenase-2 (COX-2) [19-21]. In the current study, we utilized an in vitro model of obesity to investigate the impact of obesity-associated systemic factors on the aromatasepromoting paracrine interaction between ERa-positive breast cancer cells and preadipocytes. After establishing that obesity-associated systemic IL-6 does enhance this interaction, we demonstrated that it results in greater breast cancer cell ERa activity and proliferation, suggesting that it may be one mechanism by which obesity promotes a worse breast cancer prognosis.

\section{Materials and methods}

\section{Serum samples}

Serum was collected from 25 postmenopausal breast cancer patients under an IRB approved biorepository collection protocol at the CTRC of UTHSCSA as described previously [22]. BMI was calculated, and serum was pooled according to the BMI category of the patient (normal weight $\left(18.5-24.9 \mathrm{~kg} / \mathrm{m}^{2}\right)$ or obese $\left(230.0 \mathrm{~kg} / \mathrm{m}^{2}\right)$ ).

\section{Cell lines and reagents}

MCF-7 and T47D breast cancer cells (ATCC) were maintained in IMEM (GIBCO Life Technologies) supplemented with $10 \%$ fetal bovine serum (FBS). Pre-adipocytes isolated from women undergoing elective surgical procedures were a generous gift from Dr. Rong Li, UTHSCSA, and have been described previously [23]. They were maintained in DMEM/ F12 1:1 media (GIBCO Life Technologies) plus $10 \%$ FBS. Celecoxib, human recombinant insulin, testosterone, and anastrozole were purchased from Sigma-Aldrich (St. Louis, MO) and human recombinant IL-6, tumor necrosis factor alpha (TNF-a), leptin, and insulin-like growth factor 1 (IGF-1) from R\&D Systems (Minneapolis, MN). The IL-6 depleting antibody was produced by EMD Millipore (Billerica, MA).

\section{MCF-7 cell conditioned media}

MCF-7 cell conditioned media (CM) were generated by seeding $2 \times 10^{5}$ MCF-7 cells per well in 6-well plates, allowing them to grow for $24 \mathrm{~h}$, serum-starving the cells for $18 \mathrm{~h}$, and exposing them to a $2 \%$ concentration of the pooled sera samples in serum-free media (SFM) for $1 \mathrm{~h}$. The sera were then removed and cells washed once with phosphate buffered saline followed by incubation in SFM for $24 \mathrm{~h}$. The resulting CM were collected and stored at -20 ${ }^{\circ} \mathrm{C}$ for subsequent in vitro assays. 


\section{MCF-7/pre-adipocyte conditioned media}

MCF-7/pre-adipocyte co-culture CM were generated by seeding $1 \times 10^{5}$ MCF-7 cells on top of confluent pre-adipocytes seeded in 6-well plates. After a $24 \mathrm{~h}$ incubation, the co-culture was serum-starved for $18 \mathrm{~h}$, exposed to a $2 \%$ concentration of the pooled sera in SFM for 1 $\mathrm{h}$, then washed once with PBS, and incubated for $24 \mathrm{~h}$ in SFM ? testosterone $(100 \mathrm{nM})$ and \pm anastrozole $(1 \mathrm{uM})$. The resulting $\mathrm{CM}$ were collected and stored at $-20{ }^{\circ} \mathrm{C}$.

\section{Quantitative RT-PCR}

MCF-7 cell PTGS2 (COX-2) mRNA levels were measured following a $18 \mathrm{~h}$ serumstarvation period (baseline level) and a $1 \mathrm{~h}$ exposure to a $2 \%$ concentration of pooled patient sera in SFM. mRNA levels were also assessed after 12 and $24 \mathrm{~h}$ in SFM (following the removal of the sera). Pre-adipocyte CYP19A1 (aromatase) mRNA levels were assessed following a $24 \mathrm{~h}$ incubation in MCF-7 CM. To assess the impact of MCF-7 cell COX-2 inhibition on pre-adipocyte aromatase expression, the MCF-7 cells were pre-treated with 30 $\mathrm{uM}$ celecoxib for $1 \mathrm{~h}$ prior to and during sera exposure when generating the MCF-7 CM. IL-6, TNF-a, leptin, insulin, and free IGF-1 levels in the obese versus normal weight patient sera samples were previously measured [22]. To examine whether these factors contribute to the aromatase-promoting paracrine interaction between breast cancer cells and preadipocytes, each factor was added back to the pooled normal weight patient sera. With the exception of IGF-1, the amount of each factor added was determined by the difference in average concentration between the obese and normal weight patients' serum samples. There was no significant difference in free IGF-1 found in our samples, so it was added in an amount typically used in cell culture experiments $(20 \mathrm{ng} / \mathrm{ml})$. Aromatase expression was then measured in pre-adipocytes exposed to MCF-7 cell CM generated with this enhanced normal weight sera as well as MCF-7 CM generated with non-enhanced obese and normal weight sera. To further examine the role of serum IL-6, the pooled sera samples were incubated with or without an IL-6 depleting antibody $(10 \mathrm{ug} / \mathrm{ml})$ for $1 \mathrm{~h}$ at room temperature prior to use of the sera for MCF-7 cell CM generation. MCF-7 and T47D TFF1 (pS2) and CCND1 (cyclin D1) mRNA levels were measured after a $24 \mathrm{~h}$ incubation in MCF-7/preadipocyte co-culture CM supplemented with $2 \%$ charcoal-stripped (CS)-FBS. All cells were serum-starved for $18 \mathrm{~h}$ prior to exposure to sera or CM. The methods used for RNA isolation, reverse transcription, and quantitative RT-PCR, as well as the primer sequences used, have been previously reported [24].

\section{Prostaglandin E2 concentration}

The concentration of prostaglandin E2 in MCF-7 CM was measured using the Prostaglandin E2 Parameter Assay Kit from R\&D Systems (Minneapolis, MN).

\section{Cell proliferation}

MCF-7 and T47D cell proliferation were measured using cell counting by hemocytometer as described previously [24] following a $48 \mathrm{~h}$ incubation in MCF-7/pre-adipocyte co-culture CM supplemented with $2 \%$ CS-FBS. 


\section{Statistical analysis}

Differences between cells exposed to two different experimental conditions were measured using Student's $t$ test. The results from experiments involving more than one independent variable were analyzed by two-way ANOVA. A $p$ value of $<0.05$ was considered significant.

\section{Results}

\section{Pre-adipocyte aromatase expression is induced by obesity-associated circulating factors via stimulation of breast cancer cell PGE2 production}

Given that breast cancer cells are known to produce factors, including PGE2, that promote pre-adipocyte aroma-tase expression, we began by examining whether obesity-associating circulating factors could enhance this paracrine interaction. To mimic the tumor microenvironment of an obese versus normal weight patient, we utilized an in vitro model in which cultured cells were exposed to postmenopausal breast cancer patient sera samples pooled according to BMI category (normal weight $(\mathrm{N}): 18.5-24.9 \mathrm{~kg} / \mathrm{m}^{2}$; obese (OB): 230 $\mathrm{kg} / \mathrm{m}^{2}$ ). The characteristics of the serum donors have been previously described [22]. Conditioned media from MCF-7 breast cancer cells exposed to OB or N patient sera (OB$\mathrm{CM}$ or N-CM, respectively) for one hour were generated. Pre-adipocytes cultured in OB$\mathrm{CM}$ had $89 \%$ higher aromatase expression in comparison to N-CM $(p<0.05)$ (Fig. 1a). One factor known to induce aroma-tase expression is PGE2, which is produced via a reaction catalyzed by $\mathrm{COX}-2$. Following a one hour exposure to $\mathrm{OB}$ versus $\mathrm{N}$ patient sera, there was no significant difference in MCF-7 cell COX-2 expression between these conditions or in comparison to baseline expression. However, COX-2 expression continued to increase during $24 \mathrm{~h}$ of incubation in SFM following sera removal, with the expression in cells exposed to OB patient sera increasing to a greater degree. At $24 \mathrm{~h}, \mathrm{COX}-2$ expression in the MCF-7 cells that had been exposed to OB patient sera was $40 \%$ higher than $\mathrm{N}(p<0.05)$ (Fig. 1b). This methodology corresponds to the conditions under which the MCF-7 CM was generated, with the $24 \mathrm{~h}$ time point reflecting COX-2 expression at the time of $\mathrm{CM}$ collection. Intriguingly, the PGE2 concentration in MCF-7 cell OB-CM was approximately 12 -fold higher $(p<0.05)$ than N-CM (Fig. 1c). Celecoxib treatment was then used to determine whether this OB patient sera-induced COX-2 expression and PGE2 production contribute to the OB-CM's enhancement of pre-adipocyte aromatase expression. COX-2 inhibition in MCF-7 cells during CM generation significantly decreased the pre-adipocyte aromatase expression levels induced by both $\mathrm{OB}$ and N-CM $(p<0.05)$, eliminating the difference between the two conditions (Fig. 1d). Finally, the OB sera-induced increase in aromatase expression was correlated with a threefold amplification in pre-adipocyte estradiol production in the presence of exogenous testosterone, the substrate for aromatase (Fig. 1e). Treatment with the aromatase inhibitor anastrozole following sera exposure negated the difference between $\mathrm{OB}$ and $\mathrm{N}$, indicating that this difference in estradiol production was due to the OB sera's indirect effect on aromatase expression. 


\section{Obesity-associated systemic IL-6 indirectly stimulates pre-adipocyte aromatase expression}

We have previously shown that the serum IL-6, TNF- $a$, and leptin concentrations in our obese patient population were significantly elevated in comparison to normal weight patients. Serum insulin levels in the obese patients were also four-fold higher, but there was no significant variance in free IGF-1 concentration [22]. Our next aim was to determine whether any of these obesity-associated systemic factors contribute to the promotion of the aromatase-enhancing paracrine interaction between breast cancer cells and pre-adipocytes. To this end, we repeated our measurement of MCF-7 CM-stimulated pre-adipocyte aromatase expression with the addition of each factor to the pooled $\mathrm{N}$ patient sera during $\mathrm{CM}$ generation. For IL-6, TNF-a, leptin, and insulin, the amount of each factor added was determined by the difference in average concentration between the $\mathrm{OB}$ and $\mathrm{N}$ patients' serum samples. Because others have shown IGF-1 to be increased with obesity [25, 26], we also included a condition with IGF-1 added to the $\mathrm{N}$ patient sera. OB-CM stimulated approximately two-fold greater pre-adipocyte aromatase expression in comparison to N-CM $(p<0.05)$. The addition of IL-6 or TNF-a to the N patient sera during MCF-7 CM generation significantly increased the resulting CM's effect on pre-adipocyte aromatase expression, with IL-6 having the greatest effect $(p<0.05)$. The addition of both IL- 6 and TNF-a or all five factors to the $\mathrm{N}$ sera did not produce $\mathrm{CM}$ that further enhanced aromatase expression above the addition of IL-6 alone (Fig. 2a). To confirm that IL-6 was the primary factor in the $\mathrm{OB}$ patient sera mediating its indirect enhancement of pre-adipocyte aromatase expression, we next added an IL- 6 depleting antibody to both the OB and N patient sera and then utilized this sera to generate MCF-7 CM. Aromatase expression in pre-adipocytes exposed to OB or N-CM produced with IL-6-depleted sera was significantly reduced in comparison to the OB or N-CM generated with untreated sera $(p<0.05)$, and the IL-6 depletion eliminated the difference between the OB and N-CM conditions (Fig. 2b). This demonstrates that IL-6 is the primary mediator of the OB patient sera's aromatase-enhancing effects.

\section{Obesity-associated pre-adipocyte aromatase expression enhances breast cancer cell ERa activity and proliferation}

To examine whether the observed obesity-associated increase in pre-adipocyte aromatase expression could promote breast cancer progression, we first assessed whether it was associated with higher breast cancer cell ERa activity. CM from a co-culture of MCF-7 cells and pre-adipocytes were generated by exposing the cells to either OB or $\mathrm{N}$ patient sera, then incubating them in SFM plus testosterone, the latter serving as the substrate for aromatase. Expression of the ERa target gene pS2 was 76 and $80 \%$ higher $(p<0.05)$ in MCF-7 and T47D breast cancer cells, respectively, cultured in OB versus N-CM. Expression levels of cyclin D1, another ERa target gene, were also elevated $(p<0.05)$ in the same cell lines following exposure to OB versus N-CM (Fig. 3a, b). Aromatase inhibition by anastrozole during $\mathrm{CM}$ generation reduced OB-CM-stimulated $\mathrm{pS} 2$ expression in the MCF-7 and T47D cells $(p<0.05)$, neutralizing the difference between OB and N-CM in $\mathrm{pS} 2$ expression. Aromatase inhibition resulted in a similar decrease in the levels of OB-CM-induced cyclin D1 expression in both cell lines $(p<0.05)$. However, OB-CM plus anastrozole still 
stimulated significantly greater cyclin D1 levels in comparison to $\mathrm{N}-\mathrm{CM}$ plus anastrozole ( $p$ $<0.05)$. These results closely correlated with the co-culture CM's effect on breast cancer cell proliferation (Fig. 4a, b). MCF-7 and T47D cells cultured in OB versus N-CM demonstrated 45 and $68 \%$ greater proliferation levels $(p<0.05)$. The addition of anastrozole during $\mathrm{CM}$ generation reduced OB-CM-stimulated proliferation $(p<0.05)$, but not to the level of N-CM without anastrozole.

\section{Discussion}

Numerous studies have shown a positive association between obesity and a poor breast cancer prognosis, with the strongest effects frequently seen in postmenopausal, ERapositive patients $[3-8,27]$. Obesity has also been linked to a reduced response to aromatase inhibitor therapy [12-14], suggesting that it may promote breast cancer progression in this specific patient population via enhancement of local aromatase expression. In the current study, we establish that an obesity-associated elevation in systemic levels of the proinflammatory cytokine IL-6 promotes a PGE2-mediated paracrine interaction between breast cancer cells and pre-adipocytes, resulting in greater pre-adipocyte aromatase expression.

Bulun et al. have previously demonstrated that preadipocyte aromatase expression is stimulated by a host of secretory products, including PGE2, found in MCF-7 breast cancer cell CM. While PGE2 is known to be independently capable of stimulating aromatase expression in pre-adipocytes, the other breast cancer cell secretory products also make significant contributions to the conditioned media's effect. In fact, stimulation of preadipocyte aromatase expression via MCF-7 cell CM exposure persists with inhibition of breast cancer cell COX-2 activity, clearly showing that other factors are involved in this paracrine interaction $[17,28]$. Breast cancer cells also release TNFa and interleukin-11 (IL-11), cytokines that inhibit the expression of adipogenic transcription factors and thereby prevent pre-adipocyte differentiation into mature adipocytes [29]. Given that aromatase is expressed primarily in the undifferentiated fraction of adipose tissue [17, 30, 31], this accrual of pre-adipocytes in the tumor- adjacent breast tissue also enhances local aromatase expression.

For this study, we focused on how obesity affects breast cancer cell production of secretory factors that directly stimulate pre-adipocyte aromatase expression. We were specifically interested in exploring whether obesity promotes greater breast cancer cell PGE2 production because IL- 6 has been shown to stimulate COX-2 expression in a number of cell types, and concentrations of this cytokine were significantly elevated in our obese patient serum samples [19-22]. In addition, the pathways by which PGE2 stimulates pre-adipocyte aromatase expression have been well-characterized [32, 33]. Consequently, we hypothesized that systemic factors known to be increased with obesity, including IL-6, stimulate greater MCF-7 cell COX-2 expression and PGE2 production, resulting in higher pre-adipocyte aromatase expression and a subsequent increase in breast cancer cell ERa activity and proliferation. Conditioned media from MCF-7 cells exposed to obese versus normal weight patient sera, which was shown to contain a higher concentration of PGE2, did stimulate greater pre-adipocyte aromatase expression. An elevation in MCF-7 cell COX-2 expression and PGE2 production were responsible for this effect. Thus, while other aromatase- 
promoting factors may be present in MCF-7 cell CM, the production of these does not appear to vary significantly with exposure to obese versus normal weight patient sera. In addition, our results indicate that an obesity-associated elevation in serum IL-6 is primarily responsible for the difference between obese versus normal weight MCF-7 CM-induced preadipocyte aromatase expression. Much of the excess systemic IL-6 found with obesity is produced by the adipose tissue [18], so local breast tissue IL-6 levels are likely also increased with obesity and contribute to this effect.

Dannenberg et al. have also investigated the link between obesity and local aromatase expression, demonstrating that obesity is associated with elevated aromatase levels in the normal breast tissue of both disease-free women and breast cancer patients. Intriguingly, even stronger correlations were found between aromatase expression and levels of breast inflammation, defined by the number of macrophage-containing crown-like structures of the breast (CLS-B), as well as PGE2 levels in the breast [34, 35]. In vitro experiments further defined the pathways mediating this effect, showing that macrophage COX-2 expression and PGE2 production promote preadipocyte aromatase expression and ERa target gene expression [35, 36]. The authors argue that this pathway may contribute to the increased breast cancer risk seen in obese postmenopausal women, but do not address how it might impact an established tumor.

Recent findings from our laboratory complement the work of Dannenberg et al. and additionally examine whether this macrophage/pre-adipocyte paracrine interaction may promote breast cancer progression. Using an in vitro model of the obese patient's tumor microenvironment, we demonstrated that obesity-associated systemic factors further enhance macrophage COX-2 expression and PGE2 production, resulting in greater preadipocyte aromatase expression as well as higher breast cancer ERa activity, proliferation, and migration [24]. However, while it is clear from our work and that of Dannenberg et al. that macrophages play a significant role in stimulating obesity-associated local aromatase expression, macrophages are not the only PGE2-producing cells within tumor-bearing breast tissue. If obesity does enhance breast cancer cell PGE2 secretion in vivo, then this would likely result in greater aromatase expression in the adjacent adipose tissue and a subsequent increase in breast cancer cell ERa activity and proliferation, as we have demonstrated here with our in vitro model. To confirm the relevance of our model, future studies of breast cancer patient tissue should examine whether correlations exist between the following: obesity, aromatase expression, and IL-6 and PGE2 levels in the tumor and tumor-adjacent adipose tissue, and tumor ERa target gene levels.

Our assessment of the impact of this aromatase-promoting paracrine interaction on ERa target gene expression revealed a significant difference between the obese and normal weight conditions. While pre-adipocyte aromatase inhibition was able to significantly reduce the obese CM-induced ERa activity, it eliminated the difference between the obese and normal weight conditions for breast cancer cell pS2, but not cyclin D1, expression. In addition, aromatase inhibition was not able to decrease obese CM-induced MCF-7 or T47D cell proliferation to the level of the normal weight $\mathrm{CM}$ without anastrozole. These results suggest that anastrozole alone may not be able to reduce the obese CM-induced preadipocyte aromatase activity down to the same level as the normal weight condition, 
resulting in significantly decreased but still elevated breast cancer cell ERa target gene and proliferation levels. Given that anastrozole was more effective at inhibiting obese CMinduced ERa target gene expression versus proliferation, it is also possible that the obese patient sera promotes the production of additional proliferation-stimulating factors in the pre-adipocytes and/or breast cancer cells. However, it seems clear that pre-adipocyte aromatase expression is playing a role in the variation between the obese and normal weight $\mathrm{CM}$ in ERa activity and proliferation. Our findings reflect a possible mechanism to explain previous studies demonstrating a reduced response to aromatase inhibitors in obese women. They also indicate that obese postmenopausal breast cancer patients may benefit from an aromatase inhibitor/COX-2 inhibitor combination treatment, as celecoxib treatment of the MCF-7 cells was able to significantly decrease MCF-7 cell CM-induced pre-adipocyte aromatase expression and neutralize the difference between the obese and normal weight conditions.

This study provides strong evidence that obesity may promote postmenopausal, hormoneresponsive breast cancer progression via an elevation in local aromatase expression. Obesity-associated IL-6 enhances breast cancer cell COX-2 expression and PGE2 production, resulting in higher levels of pre-adipocyte aromatase expression and a subsequent increase in breast cancer cell ERa activity and proliferation. Based on these results, an assessment of the clinical benefit of an aromatase inhibitor/COX-2 inhibitor combination treatment for obese, postmenopausal breast cancer patients is warranted.

\section{Acknowledgments}

LB was supported by a Predoctoral Traineeship Award from the United States Department of Defense, Breast Cancer Research Program (BCRP) of the Congressionally Directed Medical Research Programs (CDMRP) (Award Number W81XWH-11-1-0132).

\section{References}

1. Howlader, N.; Noone, AM.; Krapcho, M.; Garshell, J.; Neyman, N.; Altekruse, SF.; Kosary, CL.; Yu, M.; Ruhl, J.; Tatalovich, Z.; Cho, H.; Mariotto, A.; Lewis, DR.; Chen, HS.; Feuer, EJ.; Cronin, KA. SEER cancer statistics review, 1975-2010. National Cancer Institute; 2013. http:// seer.cancer.gov/csr/1975_2010/. [2 Sept 2014]

2. Anders CK, Hsu DS, Broadwater G, Acharya CR, Foekens JA, Zhang Y, Wang Y, Marcom PK, Marks JR, Febbo PG, Nevins JR, Potti A, Blackwell KL. Young age at diagnosis correlates with worse prognosis and defines a subset of breast cancers with shared patterns of gene expression. $\mathrm{J}$ Clin Oncol. 2008; 26:3324-3330. [PubMed: 18612148]

3. Flegal KM, Carroll MD, Kit BK, Ogden CL. Prevalence of obesity and trends in the distribution of body mass index among US adults, 1999-2010. JAMA. 2012; 307:491-497. [PubMed: 22253363]

4. Protani M, Coory M, Martin JH. Effect of obesity on survival of women with breast cancer: systematic review and meta-analysis. Breast Cancer Res Treat. 2010; 123:627-635. [PubMed: 20571870]

5. Calle EE, Rodriguez C, Walker-Thurmond K, Thun MJ. Overweight, obesity and mortality from cancer in a prospectively studied cohort of U.S. adults. N Engl J Med. 2003; 348:1625-1638. [PubMed: 12711737]

6. Chlebowski RT, Aiello E, McTiernan A. Weight loss in breast cancer patient management. J Clin Oncol. 2002; 20:1128-1143. [PubMed: 11844838]

7. Senie RT, Rosen PP, Rhodes P, Lesser ML, Kinne DW. Obesity at diagnosis of breast carcinoma influences duration of disease-free survival. Ann Intern Med. 1992; 116:26-32. [PubMed: 1727092] 
8. Majed B, Moreau T, Senouci K, Salmon RJ, Fourquet A, Asselain B. Is obesity an independent prognosis factor in woman breast cancer? Breast Cancer Res Treat. 2008; 111:329-342. [PubMed: 17939036]

9. McTiernan A, Wu L, Chen C, Chlebowski R, Mossavar-Rahmani Y, Modugno F, Perri MG, Stanczyk FZ, Van Horn L, Wang CY. Relation of BMI and physical activity to sex hormones in postmenopausal women. Obesity. 2006; 14:1662-1677. [PubMed: 17030978]

10. Hankinson SE, Willett WC, Manson JE, Hunter DJ, Colditz GA, Stampfer MJ, Longcope C, Speizer FE. Alcohol, height, and adiposity in relation to estrogen and prolactin levels in postmenopausal women. J Natl Cancer Inst. 1995; 87:1297-1302. [PubMed: 7658481]

11. Cauley JA, Gutai JP, Kuller LH, LeDonne D, Powell JG. The epidemiology of serum sex hormones in postmenopausal women. Am J Epidemiol. 1989; 129:1120-1131. [PubMed: 2729251]

12. Sestak I, Distler W, Forbes JF, Dowsett M, Howell A, Cuzick J. Effect of body mass index on recurrences in tamoxifen and anastrozole treated women: an exploratory analysis from the ATAC trial. J Clin Oncol. 2010; 28:3411-3415. [PubMed: 20547990]

13. Schmid P, Possinger K, Bohm R, Chaudri H, Verbeek A, Grosse Y, Luftner D, Petrides P, Sezer O, Wischnewsky M. Body mass as predictive parameter for response and time to progression (TTP) in advanced breast cancer patients treated with letrozole or megestrol acetate. Proc Annu Meet Am Soc Clin Oncol. 2000; 2000:19.

14. Folkerd EJ, Dixon JM, Renshaw L, A'Hern RP, Dowsett M. Suppression of plasma estrogen levels by letrozole and anastrozole is related to body mass index in patients with breast cancer. J Clin Oncol. 2012; 30:2977-2980. [PubMed: 22802308]

15. Suzuki T, Miki Y, Ohuchi N, Sasano H. Intratumoral estrogen production in breast carcinoma: significance of aromatase. Breast Cancer. 2008; 15:270-277. [PubMed: 18622573]

16. O'Neill JS, Elton RA, Miller WR. Aromatase activity in adipose tissue from breast quadrants: a link with tumour site. Br Med J. 1988; 296:741-743. [PubMed: 3126957]

17. Zhou J, Gurates B, Yang S, Sebastian S, Bulun SE. Malignant breast epithelial cells stimulate aromatase expression via promoter II in human adipose fibroblasts: an epithelial-stromal interaction in breast tumors mediated by C/EBPbeta. Cancer Res. 2001; 61:2328-2334. [PubMed: 11280806]

18. Fain JN. Release of interleukins and other inflammatory cytokines by human adipose tissue is enhanced in obesity and primarily due to the nonfat cells. Vitam Horm. 2006; 74:443-477. [PubMed: 17027526]

19. Maihofner C, Charalambous MP, Bhambra U, Lightfoot T, Geisslinger G, Gooderham NJ. Expression of cyclooxygenase-2 parallels expression of interleukin-1beta interleukin-6, and NKkappaB in human colorectal cancer. Carcinogenesis. 2003; 24:665-671. [PubMed: 12727794]

20. Falcone DJ, Sakamoto J, Steenport ML, Khan KM, Du B, Dannenberg AJ. Interleukin 6 stimulates macrophage MMP-9 expression via COX-2 dependent induction of PGE2 synthesis and engagement of the EP4 receptor. FASEB J. 2007; 21(383):3.

21. Geng Y, Blanco FJ, Cornelisson M, Lotz M. Regulation of cyclooxygenase-2 expression in normal human articular chondrocytes. J Immunol. 1995; 155:796-801. [PubMed: 7608556]

22. Bowers LW, Cavazos DA, Brenner AJ, Hursting SD, Maximo IX, Degraffenried LA. Obesity enhances nongenomic estrogen receptor crosstalk with the PI3K/Akt and MAPK pathways to promote in vitro measures of breast cancer progression. Breast Cancer Res. 2013; 15:R59. [PubMed: 23880059]

23. Ghosh S, Choudary A, Ghosh S, Musi N, Hu Y, Li R. IKKbeta mediates cell shape-induced aromatase expression and estrogen biosynthesis in adipose stromal cells. Mol Endocrinol. 2009; 23:662-670. [PubMed: 19221050]

24. Bowers LW, Maximo IX, Brenner AJ, Beeram M, Hursting SD, Price RS, Tekmal RR, deGraffenried LA. NSAID use reduces breast cancer recurrence in overweight and obese women: role of prostaglandin-aromatase interactions. Cancer Res. 2014; 74:4446-4457. [PubMed: 25125682]

25. Nam SY, Lee EJ, Kim KR, Cha BS, Song YD, Lim SK, Lee HC, Huh KB. Effect of obesity on total and free insulin-like growth factor (IGF)-1, and their relationship to IGF-binding protein 
(BP)-1, IGFBP-2, IGFBP-3, insulin, and growth hormone. Int J Obes Relat Metab Disord. 1997; 21:355-359. [PubMed: 9152736]

26. Frystyk J, Vestbo E, Skjaerbaek C, Mogensen CE, Orskov H. Free insulin-like growth factor in human obesity. Metabolism. 1995; 44:37-44. [PubMed: 7476310]

27. Wolters R, Schwentner L, Regierer A, Wischnewsky M, Kreienberg R, Wöckel A. Endocrine therapy in obese patients with primary breast cancer: another piece of evidence in an unfinished puzzle. Breast Cancer Res Treat. 2011; 131:925-931. [PubMed: 22080246]

28. Meng L, Zhou J, Sasano H, Suzuki T, Zeitoun KM, Bulun SE. Tumor necrosis factor alpha and interleukin 11 secreted by malignant breast epithelial cells inhibit adipocyte differentiation by selectively down-regulating CCAAT/enhancer binding protein alpha and peroxisome proliferatoractivated receptor gamma: mechanism of desmoplastic reaction. Cancer Res. 2001; 61:2250-2255. [PubMed: 11280794]

29. Ackerman GE, Smith ME, Mendelson CR, MacDonald PC, Simpson ER. Aromatization of androstenedione by human adipose tissue stromal cells in monolayer culture. J Clin Endocrinol Metab. 1981; 53:412-417. [PubMed: 7251819]

30. Price T, Aitken J, Head J, Mahendroo M, Means G, Simpson E. Determination of aromatase cytochrome $\mathrm{P} 450$ messenger ribonucleic acid in human breast tissue by competitive polymerase chain reaction amplification. J Clin Endocrinol Metab. 1992; 74:1247-1252. [PubMed: 1592866]

31. Deb S, Zhou J, Amin SA, Imir AG, Yilmaz MB, Lin Z, Bulun SE. A novel role of sodium butyrate in the regulation of cancer-associated aromatase promoters I. 3 and II by disrupting a transcriptional complex in breast adipose fibroblasts. J Biol Chem. 2006; 281:2585-2597. [PubMed: 16303757]

32. Chen D, Reierstad S, Lin Z, Lu M, Brooks C, Li N, Innes J, Bulun SE. Prostaglandin E(2) induces breast cancer related aromatase promoters via activation of p38 and c-Jun $\mathrm{NH}(2)$-terminal kinase in adipose fibroblasts. Cancer Res. 2007; 67:8914-8922. [PubMed: 17875734]

33. Chen D, Reierstad S, Fang F, Bulun SE. JunD and JunB integrate prostaglandin E2 activation of breast cancer-associated proximal aromatase promoters. Mol Endocrinol. 2011; 25:767-775. [PubMed: 21393445]

34. Morris PG, Hudis CA, Giri D, Morrow M, Falcone DJ, Zhou XK, Du B, Brogi E, Crawford CB, Kopelovich L, Subbaramaiah K, Dannenberg AJ. Inflammation and increased aromatase expression occur in the breast tissue of obese women with breast cancer. Cancer Prev Res. 2011; 4:1021-1029.

35. Subbaramaiah K, Morris PG, Zhou XK, Morrow M, Du B, Giri D, Kopelovich L, Hudis CA, Dannenberg AJ. Increased levels of COX-2 and prostaglandin E2 contribute to elevated aromatase expression in inflamed breast tissue of obese women. Cancer Discov. 2012; 2:356-365. [PubMed: 22576212]

36. Subbaramaiah K, Howe LR, Bhardwaj P, Du B, Gravaghi C, Yantiss RK, Zhou XK, Blaho VA, Hla T, Yang P, Kopelovich L, Hudis CA, Dannenberg AJ. Obesity is associated with inflammation and elevated aromatase expression in the mouse mammary gland. Cancer Prev Res. 2011; 4:329_ 346. 

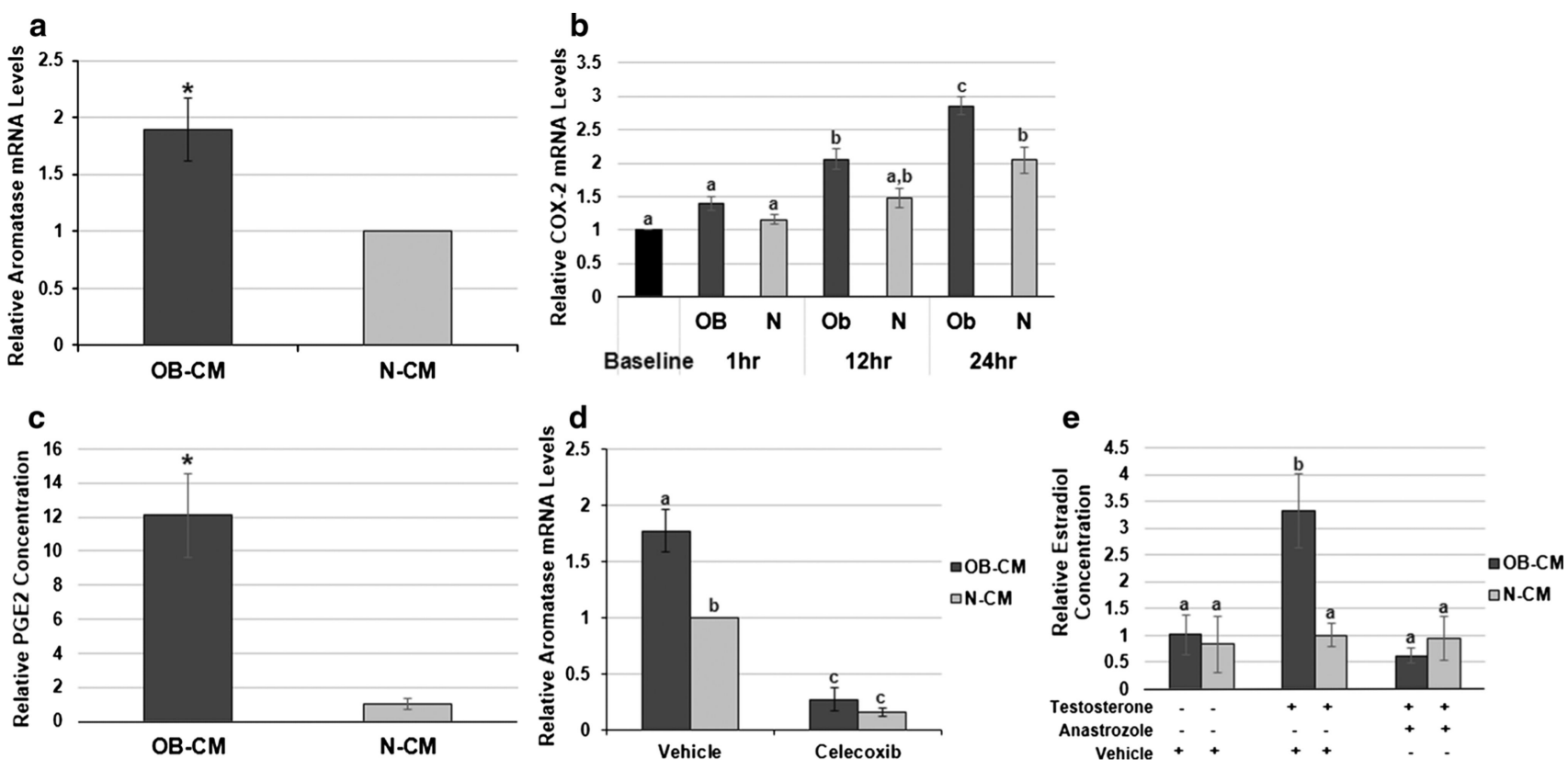

Fig. 1.

Obesity-associated circulating factors promote pre-adipocyte aromatase expression via stimulation of breast cancer cell COX-2 expression and PGE2 production. a Aromatase expression in preadipocytes incubated in MCF-7 cell CM generated following obese versus normal weight patient sera exposure (OB-CM and N-CM). b COX-2 expression in MCF-7 cells after an 18-hour serum-starvation period (Baseline), $1 \mathrm{~h}$ of sera exposure (OB and N, 1 $\mathrm{h}$ ), $12 \mathrm{~h}$ after removal of the sera (OB and N, $12 \mathrm{~h}$ ), and $24 \mathrm{~h}$ after removal of the sera (OB and N, $24 \mathrm{~h}$ ). $c$ Relative amount of PGE2 produced by MCF-7 cells following exposure to $\mathrm{OB}$ or $\mathrm{N}$ patient sera (OB-CM and $\mathrm{N}-\mathrm{CM}$ ). $\mathbf{d}$ Aromatase expression in pre-adipocytes incubated in MCF-7 cell CM generated following patient sera exposure (OB-CM and N$\mathrm{CM}$ ) plus vehicle or celecoxib treatment. e Relative amount of estradiol in CM from a $\mathrm{MCF}-7 /$ pre-adipocyte co-culture exposed to patient sera (OB-CM and N-CM), then incubated in SFM with vehicle, testosterone, and/or anastrozole. Data shown represents the average of at least three independent experiments. Asterisks indicate significant differences in comparison to N-CM; different letters indicate significant differences, $p<0.05$ 

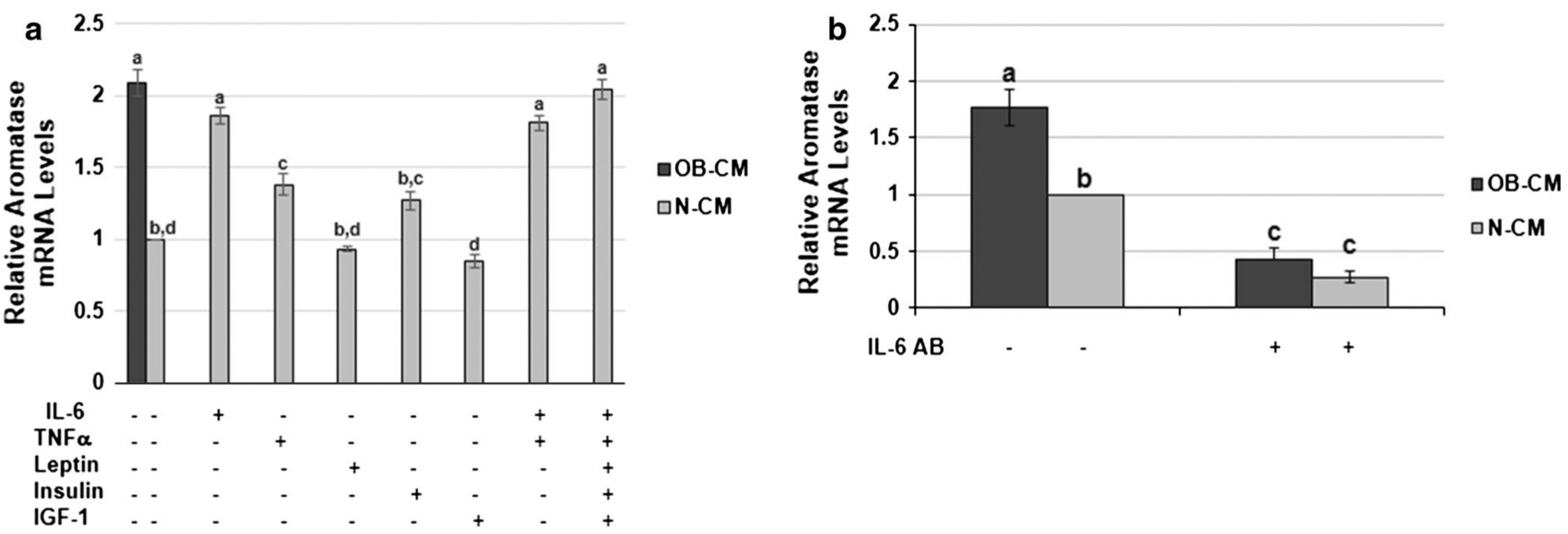

Fig. 2.

Pre-adipocyte aromatase expression is indirectly stimulated by obesity-associated systemic IL-6. a Aromatase expression in preadipocytes exposed to MCF-7 cell CM generated following patient sera exposure alone (OB-CM and $\mathrm{N}-\mathrm{CM})$ or $\mathrm{N}$ patient sera plus one of five obesity-associated circulating factors, including IL-6, TNF-a, leptin, insulin, and IGF-1. b Aromatase expression in pre-adipocytes exposed to MCF-7 cell CM generated following exposure to patient sera (OB-CM and N-CM) that was or was not pre-treated with an IL-6 depleting antibody (IL-6 AB). Data shown represents the average of at least three independent experiments. Different letters indicate significant differences, $p<0.05$ 

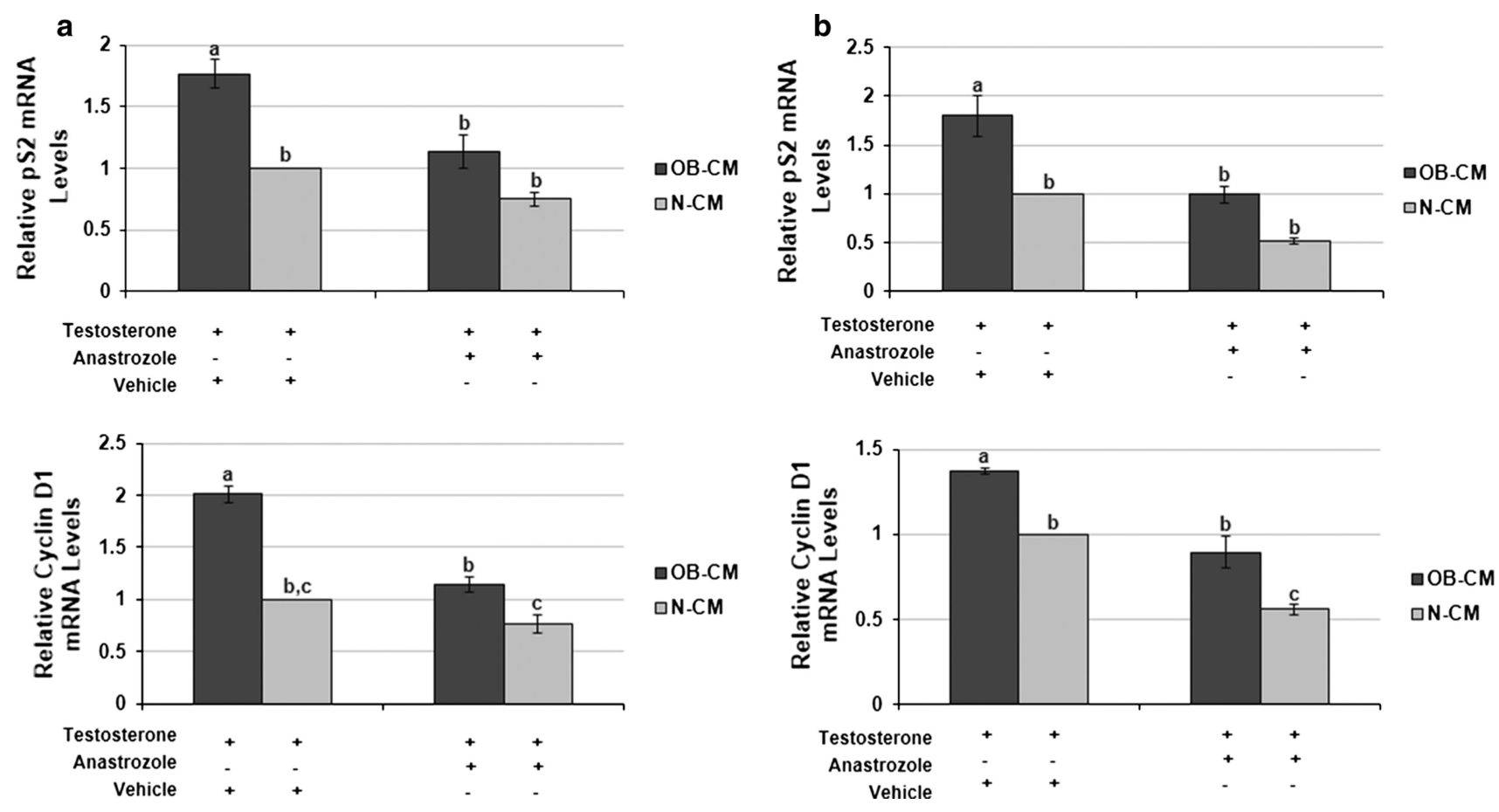

Fig. 3.

Obesity-associated pre-adipocyte aromatase expression enhances breast cancer cell ERa activity. The impact of MCF-7/pre-adipocyte co-culture CM on ERa activity in MCF-7 (a) and T47D (b) cells, as measured by qPCR analysis of pS2 and cyclin D1 expression. Experimental conditions include CM from co-cultures exposed to patient sera (OB-CM, N$\mathrm{CM}$ ) followed by incubation in SFM with testosterone plus vehicle or testosterone plus anastrozole. Data shown represents the average of at least three independent experiments. Different letters indicate significant differences, $p<0.05$ 

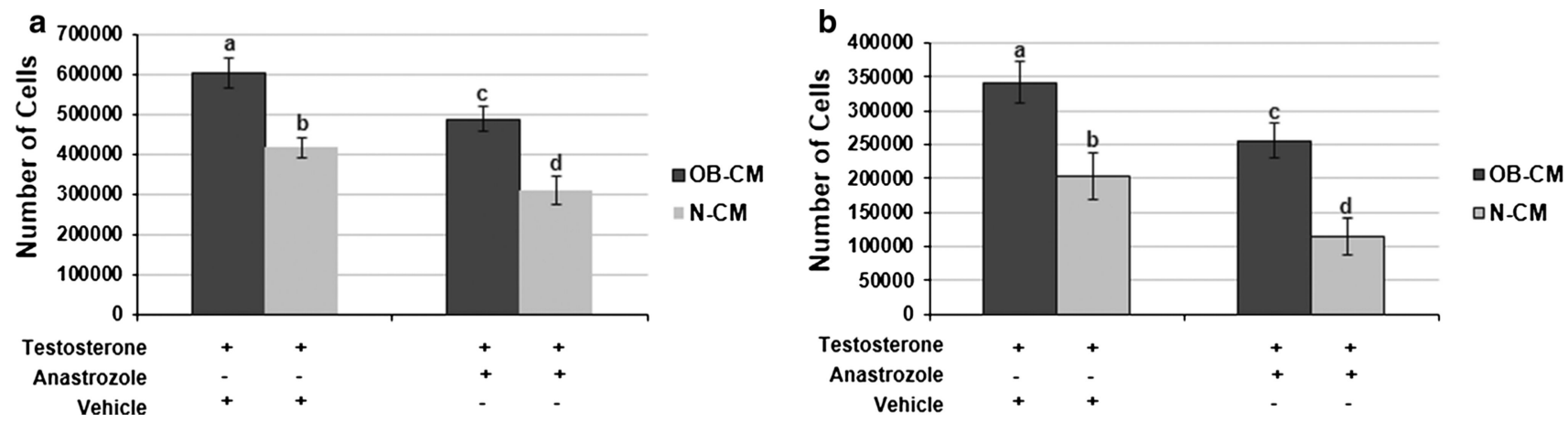

Fig. 4.

Breast cancer cell proliferation is increased by obesity-induced pre-adipocyte aromatase expression. MCF-7 (a) and T47D (b) breast cancer cell proliferation in response to culture in MCF-7/pre-adipocyte co-culture CM. Experimental conditions include CM from co-cultures exposed to patient sera (OB-CM, N-CM) followed by incubation in SFM with testosterone plus vehicle or testosterone plus anastrozole. Data shown represents the average of at least three independent experiments. Different letters indicate significant differences, $p<0.05$ 